\title{
\begin{tabular}{c|c|}
\hline Jurnal Abdimas Saintika & e-ISSN : 2715-4424 \\
p-ISSN :2746-797X \\
\hline
\end{tabular}
}

\section{PEMBERIAN EDUKASI TENTANG HIPERTENSI DENGAN MEDIA WHATSAPP BLAST DI PUSKESMAS DADOK TUNGGUL HITAM KOTA PADANG}

\author{
Annisa Novita Sary ${ }^{1 *}$, Melia Pebrina ${ }^{2}$, Sandra Hardini ${ }^{3}$ \\ 1,2,3Program Studi S1 Kesehatan Masyarakat, Stikes Syedza Saintika \\ *Email : annisa.novita1011@gmail.com
}

\begin{abstract}
ABSTRAK
Hipertensi merupakan penyakit tidak menular yang menjadi salah satu penyebab utama kematian di dunia. Berdasarkan data Puskesmas Dadok Tunggul Hitam terdapat kasus dengan diagnosa hipertensi sebanyak 5.587 jiwa (2018) meningkat menjadi 6.367 jiwa (2019). Salah satu intervensi yang dapat dilakukan yaitu pemberian edukasi tentang hipertensi. Kegiatan dilaksanakan di Puskesmas Dadok Tunggul Hitam pada bulan September 2020. Kegiatan diawali dengan pemberian pre test untuk melihat tingkat pengetahuan masyarakat tentang penyakit hipertensi, kemudian pemberian edukasi kesehatan tentang penyakit hipertensi. Pelaksanaan penyuluhan kesehatan dilaksanakan dengan memberikan edukasi terkait hipertensi kepada masyarakat melalui media Whatsapp Blast, dan diakhiri dengan post test untuk mengukur peningkatan pengetahuannya. Hasil dari kegiatan pengabdian masyarakat terhadap pasien yang terdiagnosis penyakit hipertensi dari 15 orang pasien terdapat 5 orang $(33 \%)$ memiliki tingkat pengetahuan yang baik tentang hipertensi sebelum diberikan penyuluhan. Setelah diberikan penyuluhan secara daring melalui media Whatsapp Blast dari 15 orang pasien terdapat 12 orang $(80 \%)$ memiliki pengetahuan yang baik tentang hipertensi dan upaya pencegahannya. Dapat disimpulkan adanya pengingkatan pengetahuan tentang upaya pencegahan hipertensi setelah diberikan edukasi dengan media Whatsapp Blast. Disarankan agar pemberian edukasi dengan media Whatsapp Blast dapat dilakukan bagi petugas kesehatan dalam memberikan promosi kesehatan kepada masyarakat tentang pencegahan penyakit hipertensi.
\end{abstract}

Kata Kunci: Hipertensi; media whatsapp blast; edukasi

\section{ABSTRACT}

Hypertension is a non-communicable disease which is one of the main causes of death in the world. Based on data from the Public Health Center Dadok Tunggul Hitam, there were cases of hypertension from 5,587 people (2018), increase to 6,367 people (2019). The intervention from this case by providing education about hypertension. The activity was carried out at the Public Health Center Dadok Tunggul Hitam in September 2020. The activity started by giving a pre test about hypertension, then providing health education about hypertension. The health education is delivered through the Whatsapp Blast media, and ends with a post test. The results of the activities for patients diagnosed with hypertension, from 15 patients there were 5 patients (33\%) who had a good level of knowledge before given education. After given education through Whatsapp Blast media, there were 12 patients (80\%) who had good knowledge about hypertension and its prevention efforts. It can be concluded that there is an increase in knowledge about hypertension and prevention after given education through Whatsapp Blast media. It is suggested that education using Whatsapp Blast media can be carried out for health workers in providing health promotion to the public regarding the prevention of hypertension.

Keywords: Hypertension; whatsapp blast media; education 


\section{Jurnal Abdimas Saintika}

\section{PENDAHULUAN}

Hipertensi adalah peningkatan tekanan darah sistolik sedikitnya 140 $\mathrm{mmHg}$ atau tekanan diastolik sedikitnya $90 \mathrm{mmHg}$ (Price, dalam Nurafif A.H., \& Kusuma H, 2016). Hipertensi merupakan penyakit tidak menular yang menjadi salah satu penyebab utama kematian premature di dunia (Pusdatin RI, 2018). World Health Organization (WHO) mengestimasi saat ini prevalensi hipertensi secara global sebesar $22 \%$ dari total penduduk dunia, hanya kurang seperlima yang melakukan upaya pengendalian terhadap tekanan darah yang dimiliki(WHO, 2020). Penyakit ini sering disebut sebagai the silent killer karena tidak menunjukkan gejala yang spesifik (Ibekwe, 2015).

Berdasarkan data Institute for Health Metrics and Evaluation (IHME) tahun 2017, menyatakan bahwa dari 53,3 juta kematian didunia didapatkan penyebab kematian akibat penyakit kardiovaskuler sebesar 33,1\%, kanker sebesar 16,7\%, DM dan gangguan endokrin $6 \%$ dan infeksi saluran napas bawah sebesar 4,8\%. Data penyebab kematian di Indonesia pada tahun 2016 didapatkan total kematian sebesar 1,5 juta dengan penyebab kematian terbanyak adalah penyakit kardiovaskuler $36,9 \%$, kanker 9,7\%, penyakit DM dan endokrin 9,3\% dan Tuberkulosa 5,9\%. IHME juga menyebutkan bahwa dari total 1,7 juta kematian di Indonesia didapatkan faktor risiko yang menyebabkan kematian adalah tekanan darah (hipertensi) sebesar $23,7 \%$, Hiperglikemia sebesar 18,4\%, Merokok sebesar $12,7 \%$ dan obesitas sebesar 7,7\%.

Pada tahun 2020 menunjukkan sekitar 1,13 Miliar orang di dunia menyandang hipertensi, dimana Asia Tenggara berada di posisi ke-3 tertinggi dengan prevalensi sebesar $25 \%$ terhadap total penduduk. Dengan perkiraan bahwa 1 diantara 5 orang perempuan, dan 1 diantara 4 orang laki-laki di dunia terdiagnosis hipertensi. Jumlah penyandang hipertensi terus meningkat setiap tahunnya, diperkirakan pada tahun 2025 akan ada 1,5 Miliar orang yang terkena hipertensi, dan diperkirakan setiap tahunnya 10,44 juta orang meninggal akibat hipertensi dan komplikasinya (WHO, 2020).

Hipertensi masih merupakan tantangan besar di Indonesia. Betapa tidak, hipertensi merupakan kondisi yang sering ditemukan pada pelayanan kesehatan primer kesehatan. Hal itu merupakan masalah kesehatan dengan prevalensi yang tinggi. Hipertensi juga menjadi ancaman kesehatan masyarakat karena potensinya yang mampu mengakibatkan kondisi komplikasi seperti, stroke, penyakit jantung coroner, dan ginjal (Kemenkes, 2019).

Pelayanan kesehatan pada penderita hipertensi sesuai standar merupakan upaya pencegahan sekunder di wilayah kerjanya dalam kurun waktu satu tahun. Pelayanan yang diberikan berupa pengukuran tekanan darah dilakukan minimal satu kali sebulan di fasilitas pelayanan kesehatan dan edukasi perubahan-perubahan gaya hidup dan kepatuhan minum obat oleh penderita (Profil Dinas Kesehatan Kota Padang, 2019).

Prevalensi dari hasil Riskesdas 2013 bahwa prevalensi hasil pengukuran tekanan darah, hipertensi naik dari 25,8\% menjadi 34,1\% (Riskesdas, 2018). Dan prevalensi untuk daerah Sumatera Barat yaitu sebesar $25,16 \%$ dari prevalensi sebelumnya 22,6\% (Riskesdas, 2018).

Dari 150.591 jiwa penduduk berusia $\geq 15$ tahun dengan diagnosa hipertensi pada tahun 2018, terdapat 108.104 orang yang mendapatkan 


\section{Jurnal Abdimas Saintika}

Volume 3 Nomor $1 \mid$ https://jurnal.syedzasaintika.ac.id

pelayanan hipertensi yaitu sebesar $71,79 \%$ (Profil Dinas Kesehatan Kota Padang, 2018). Sementara dari 171.594 jiwa penduduk usia $\geq 15$ tahun yang dilakukan pengukuran darah pada tahun 2019, terdapat 45.213 orang yang mendapatkan pelayanan hipertensi yaitu sebesar 26,3\% (Profil Dinas Kesehatan Kota Padang, 2019).Artinya terdapat penurunan target capaian dari tahun 2018 sebesar $71,79 \%$ menjadi $26,3 \%$ pada tahun 2019.

Berdasarkan data di Puskemas Dadok Tunggul Hitam, dari penduduk dengan diagnosa hipertensi 5.587 jiwa pada tahun 2018, yang mendapatkan pelayanan yaitu sebesar 34,80\% (1.944 jiwa) (Profil Dinas Kesehatan Kota Padang, 2018). Dan pada tahun 2019, dari 6.367 penduduk penderita hipertensi, yang mendapatkan pelayanan hanya sebesar 32,9\% (2.093 jiwa) (Profil Dinas Kesehatan Kota Padang, 2019). Berdasarkan uraian data tersebut maka tujuan dari pengabdian masyarakat ini adalah memberikan edukasi tentang penyakit hipertensi dan pencegahannya melalui meda Whatsapp Blast kepada pasien hipertensi di Puskesmas Dadok tunggul Hitam Tahun 2020.

\section{METODE}

Kegiatan pengabdian kepada masyarakat dilaksanakan di Puskesmas Dadok Tunggul Hitam pada bulan September Tahun 2020. Sasaran kegiatan ini adalah pasien hipertensi sebanyak 15 pasien. Pelaksanaan kegiatan ini dilakukan mulai dengan memberikan pre test tentang hipertensi dan pencegahannya kepada pasien hipertensi dengan alat ukur berupa google form yang dikirim melalui Whatsapp. Setelah itu diberikan edukasi secara daring melalui media Whatsapp Blast kepada sasaran. Pemberian edukasi berupa materi-materi tentang definisi, gejala, factor penyebab, dan upaya pencegahan hipertensi. Waktu pemberian edukasi dilakukan selama 40 menit. Untuk mengukur peningkatan pengetahuan pasien setelah diberikan edukasi, maka di berikan post test. Kegiatan ini dilakukan pada tanggal 24 September 2020.

\section{HASIL DAN PEMBAHASAN}

Kegiatan pengabdian kepada masyarakat dilaksanakan pada hari Kamis tanggal 24 September 2020 pukul 10.00 WIB, tempat pelaksanaan di Puskesmas Dadok Tunggul Hitam secara daring (dalam jaringan) dengan menggunakan media Whatsapp Blast. Peserta yang hadir di grup Whatsapp Blast sebanyak 15 orang pasien hipertensi. Tim penyuluh terdiri dari moderator dan penyaji. Pelaksanaan edukasi dilakukan dengan 3 tahap, yaitu:

1. Tahap Perkenalan

Sebelum kegiatan dimulai tim pengabdian masyarakat melakukan perkenalan dan dilanjutkan menjelaskan maksud dan tujuan dari materi yang diberikan dan kontrak pelaksanaan yang akan dilakukan. Disepakati bahwa pemberian edukasi dilaksanakan selama 40 menit.

2. Tahap Pemberian Edukasi

Sebelum materi diberikan pemateri melakukan penggalian pengetahuan kepada pasien hipertensi tentang materi dengan memberikan pre test Dengan mengirimkan kuesioner melalui link google form pada grup Whatsapp. Materi yang diberikan dalam bentuk power point melalui media grup Whatsapp Blast. Materi yang disampaikan ketika pemberian edukasi membahas 


\section{Jurnal Abdimas Saintika}

tentang pengertian, gejala, factor penyebab, cara pencegahan penyakit hipertensi. Disaat penyampaian materi melalui grup Whatsapp Blast, pasien hipertensi memperhatikan dan antusias dengan materi yang disampaikan. Kegiatan edukasi tentang pengendalian hipertensi untuk meningkatkan kesadaran pasien untuk peduli melakukan pemeriksaan kesehatan secara rutin dan pencegahannya melalui whatsapp blast.
3. Tahap Akhir

Sebelum materi diakhiri, moderator memberikan kesempatan kepada peserta untuk memberikan feedback tentang materi dengan cara tanya jawab. Terlihat dari jawabanpeserta cukup baik dari beberapa pertanyaan yang disampaikan oleh pemateri. Untuk mengetahui sejauh mana peningkatan pengetahuan peserta tentang hipertensi maka diberikan post test.

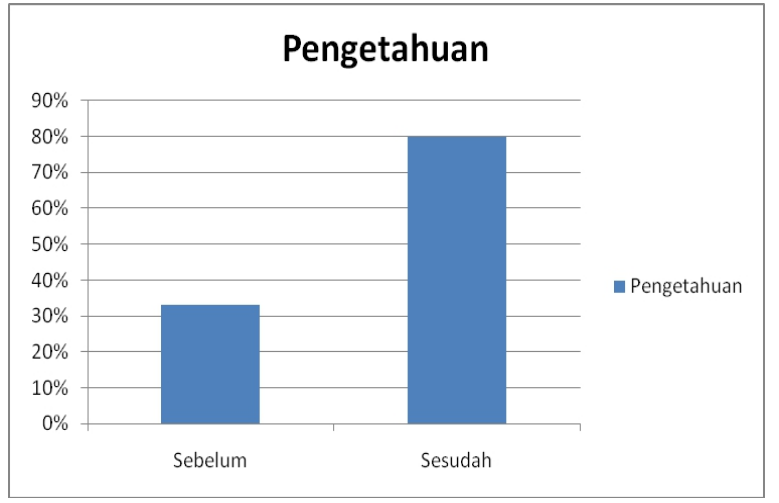

Gambar 1. Distribusi Frekuensi Tingkat Pengetahuan Pasien Sebelum dan Sesudah Dilakukan Edukasi

Ditemukan hasil pada gambar 1. bahwa dari 15 orang pasien hipertensi terdapat 5 orang $(33 \%)$ memiliki tingkat pengetahuan yang baik tentang hipertensi sebelum diberikan penyuluhan. Setelah diberikan penyuluhan secara daring melalui media Whatsapp Blast dari 15 orang pasien terdapat 12 orang $(80 \%)$ memiliki pengetahuan yang baik tentang hipertensi dan upaya pencegahannya. Terdapat peningkatan pengetahuan peserta tentang penyakit hipertensi dan pencegahannya antara sebelum dan sesudah diberikan edukasi melalui media Whatsapp Blast.

Penyakit hipertensi atau tekanan darah tinggi adalah salah satu jenis penyakit yang mematikan di dunia dan faktor risiko paling utama terjadinya hipertensi yaitu faktor usia sehingga tidak heran penyakit hipertensi sering dijumpai pada usia senja/ usia lanjut (Fauzi, 2014), sedangkan menurut Setiati (2015), hipertensi merupakan tanda klinis ketidakseimbangan hemodinamik suatu sistem kardiovaskular, di mana penyebab terjadinya disebabkan oleh beberapa faktor/ multi faktor sehingga tidak bisa terdiagnosis dengan hanya satu faktor tunggal (Setiati, 2015).

Masyarakat di wilayah kerja Puskesmas Dadok Tunggul Hitam banyak yang memiliki tekanan darah di atas 140/90 $\mathrm{mmHg}$. Hal ini diakibatkan oleh beberapa faktor risiko. Salah satunya karena kurang pengetahuan dan kesadaran masyarakat terhadap hipertensi 


\section{Jurnal Abdimas Saintika}

Volume 3 Nomor $1 \mid$ https://jurnal.syedzasaintika.ac.id

sehingga jarang melakukan kontrol terhadap kesehatannya. Kurangnya pengetahuan tadi dikarenakan karena penyuluhan tentang hipertensi di Puskesmas Dadok Tunggul Hitam yang belum terjadwal secara teratur setiap bulan. Penyakit ini sering disebut sebagai the silent killer karena tidak menunjukkan gejala yang spesifik (Ibekwe, 2015).

\section{SIMPULAN}

Terjadi peningkatan pengetahuan masyarakat tentang penyakit hipertensi dan upaya pencegahannya. Perlu dilakukan kegiatan penyuluhan dengan media Whatsapp Blast mengingat pada saat ini masih dalam kondisi pandemic Covid-19. Sehingga dapat memudahkan masyarakat untuk mendapatkan informasi-informasi kesehatan guna mencegah penyakit hipertensi.

\section{DAFTAR PUSTAKA}

Anung, S. (2019). Percepatan Pencegahan dan Pengendalian Penyakit Menuju Cakupan Kesehatan Semesta. 2019. Padang.

A, Nuarif, H.K. (2015). Aplikasi Asuhan Keperawatan Berdasarkan Diagnosa Medis dan Nanda NicNOC. Yogyakarta

Ardiansyah, M. (2012). Medikal Bedah untuk Mahasiswa. 2012. Yogyakarta

Dinas Kesehatan Sumatera Barat. (2019). Profil Kesehatan Kota Padang Tahun 2019. Padang

Dinas Kesehatan Sumatera Barat. (2018). Profil Kesehatan Kota Padang Tahun 2018. Padang

Fauzi, Isma. (2014). Buku Pintar Deteksi Dini Gejala, \& Pengobatan
Asam Urat, Diabetes, dan Hipertensi. Yogyakarta

Ignatavicius, Workman, \& Rebar. (2017. Medical Surgical Nursing:

Concepts forInterprofessional Collaborative Care (9thed.).

Irwan. (2016). Epidemiologi Penyakit Tidak Menular. Yogyakarta

Kemenkes RI. (2019). Pusat Data dan Informasi Hipertensi. InfoDATIN.https://pusdatin.kem kes.go.id/

Kowalak, J.P. (2011). Patofisiologi. Jakarta

Puskesmas Dadok Tunggul Hitam. (2019). Laporan Tahun 2019 Puskesmas Dadok Tunggul Hitam. 2018. Padang

Puskesmas Dadok Tunggul Hitam. (2019). Profil Puskesmas Dadok Tunggul Hitam Tahun 2019. Padang

P2PTM Kemenkes RI. (2019). Know Your Number, Kendalikan Tekanan Darahmu dengan CERDIK.http://p2ptm.kemkes.g o.id/kegiatan-p2ptm/dkijakarta/hari-hipertensi-dunia2019-know-your-numberkendalikan-tekanan-darahmudengan-cerdik. (online) diakses online pada tanggal 22 September 2020.

Riskesdas. (2018). Laporan Hasil Kesehatan Dasar (Riskesdas), Badan Penelitian dan Pembangunan Kesehatan, Depkes RI.

Riyadi, Sujono. (2011). Keperawatan Medikal Bedah. Yogyakarta

Setiati Siti, et al. Buku Ajar Ilmu Penyakit Dalam. 2015. Jakarta.

Smeltzer. (2013). Keperawatan Medikal Bedah. 2013. Yogyakarta

Stikes Syedza Saintika Padang. (2020). Buku Pedoman pelaksanaan 


\section{Jurnal Abdimas Saintika}

Volume 3 Nomor 1 | https://jurnal.syedzasaintika.ac.id

pengalaman belajar lapangan (PBL) Prodi Kesehatan Masyarakat Tahun 2020/2021. Padang
World Health Organization. (2020). Health Topic Hypertension 2019. (online) diakses online pada tanggal 22 September 2020. 